\title{
Coercion, Incarceration, and Chemical Castration: An Argument From Autonomy
}

\author{
Thomas Douglas • Pieter Bonte • \\ Farah Focquaert • Katrien Devolder • Sigrid Sterckx
}

Received: 19 June 2012 / Accepted: 25 January 2013 / Published online: 29 June 2013

(C) The Author(s) 2013. This article is published with open access at Springerlink.com

\begin{abstract}
In several jurisdictions, sex offenders may be offered chemical castration as an alternative to further incarceration. In some, agreement to chemical castration may be made a formal condition of parole or release. In others, refusal to undergo chemical castration can increase the likelihood of further incarceration though no formal link is made between the two. Offering chemical castration as an alternative to further incarceration is often said to be partially coercive, thus rendering the offender's consent invalid. The dominant response to this objection has been to argue that any coercion present in such cases is compatible with valid consent. In this article, we take a different tack, arguing that, even if consent would not be valid,
\end{abstract}

\footnotetext{
T. Douglas $(\bowtie)$

Oxford Uehiro Centre for Practical Ethics, Faculty of Philosophy, University of Oxford, Littlegate House, St. Ebbes Street, Oxford OX1 1PT, United Kingdom

e-mail: thomas.douglas@philosophy.ox.ac.uk

P. Bonte $\cdot$ F. Focquaert $\cdot$ K. Devolder $\cdot$ S. Sterckx Bioethics Institute Ghent, Faculty of Arts and Philosophy, Ghent University, Blandijnberg 2, 9000 Ghent, Belgium
}

S. Sterckx

Department of Philosophy and Moral Sciences,

Vrije Universiteit, Brussels, Belgium offering chemical castration will often be supported by the very considerations that underpin concerns about consent: considerations of autonomy. This is because offering chemical castration will often increase the offender's autonomy, both at the time the offer is made and in the future.

Keywords Castration (chemical) · Incarceration . Coercion $\cdot$ Autonomy $\cdot$ Authenticity

\section{Chemical Castration of Sex Offenders}

Castration has been used in several jurisdictions to prevent recidivism in sex offenders. It can be achieved either by means of a surgical procedure (so-called surgical or physical castration) or through the administration of pharmacological agents (chemical castration). The aim of both procedures is to reduce testosterone to a prepubescent level, thereby attenuating the offender's sexual urges and helping to suppress sexually deviant thinking and behaviour.

\section{History}

Compulsory surgical castration has been practised for thousands of years for various purposes, including as a 
criminal punishment (Heim and Hursch 1979). In the 20th century, voluntary or compulsory surgical castration of sex offenders was practiced in a number of U.S. states and several European countries, including Denmark, Norway, Estonia, Finland, Iceland, Latvia, The Netherlands, Switzerland, and Germany. There is no robust data on effectiveness. However, reviews of the data that are available report that, over follow-up periods ranging from 1 to 35 years, recidivism rates of 2.5-7.5 percent were found after surgical castration compared to 60-84 percent in offenders left "untreated" (Heim and Hursch 1979; Weinberger et al. 2005). ${ }^{1}$

Though its use has declined, surgical castration of sex offenders still occurs, including in the West. At present, voluntary surgical castration of sex offenders is legal in California, Florida, Iowa, Louisiana, and Texas (del Busto and Harlow 2011). In Europe, it has remained in limited use in Germany and more widespread use in the Czech Republic, where, between 2001 and 2006, more than 50 sex offenders underwent surgical castration (European Committee for the Prevention of Torture 2009).

However, from the 1960s, most jurisdictions replaced irreversible surgical castration of sex offenders with reversible chemical castration. This has typically been achieved through the administration of medroxyprogesterone acetate (MPA) or cyproterone acetate (CPA), with MPA being the agent of choice in the United States and CPA the usual agent in Europe, the Middle East, and Canada (Meyer, Cole, and Emory 1992; Gordon and Grubin 2004; Thibaut et al. 2010). CPA is licenced in more than 20 countries to lower sexual drive in adult men with paraphilias, that is, exhibitionism, frotteurism, voyeurism, fetishism, sado-

\footnotetext{
${ }^{1}$ Other reviews have found lower rates of recidivism for "untreated" sex offenders. For example, while noting many defects in the studies available, Furby, Weinrott, and Blackshaw (1989) report that sex offender recidivism rates in "untreated" offenders in North America are typically between 10 percent and 40 percent. Some studies have also found slightly higher recidivism rates in surgically castrated offenders. For example, Wille and Beier (1989) identified a recidivism rate of 11 percent over 4 years of follow-up.
}

masochism, sexual masochism, sexual sadism, paedophilia, and paraphilias "not otherwise specified" (Gordon and Grubin 2004; Thibaut et al. 2010). It has not been approved by the U.S. Food and Drug Administration (FDA) because, based on animal research data, it is suspected to induce liver cell carcinoma (Neumann et al. 1992; Kasper 2001). By contrast, MPA treatment, which is often given in the "depot" or sustained-release form Depo-Provera, was abandoned in Europe due to the severity of the side effects (Thibaut et al. 2010; see section on "Effects" below for discussion).

In the 1980 s, an additional class of pharmaceuticals for reducing recidivism in sex offenders became available: the SSRIs (selective serotonin reuptake inhibitors). SSRIs are primarily used to treat depression and anxiety disorders but may also be useful in some mild cases of sexual offending (Bradford 2001; Thibaut et al. 2010). Subsequently, new hormonal agents - the gonadotrophin-releasing hormone (GnRH) agonists - have also come into use. These drugs are primarily used to treat hormonesensitive prostate cancers. However, they dramatically reduce testosterone levels and have been used to reversibly decrease sex drive in male sex offenders.

\section{Effects}

We will understand chemical castration as the administration of CPA, MPA, or GnRH agonists where the intention is to reduce testosterone to prepubescent levels. Chemical castration of sex offenders has most frequently targeted individuals exhibiting paraphilias. Not all sex offenders suffer from paraphilia and not all paraphiliacs are sex offenders. However, paraphilias are more prevalent in sex offenders than in the general population, with exhibitionism and paedophilia being most common (Gordon and Grubin 2004; Thibaut et al. 2010). Chemical castration via administration of CPA and MPA has been found effective in reducing recidivism in sexual offenders with paraphilias in some small-scale, controlled studies (e.g., Fedoroff et al. 1992; Maletzky, Tolan, and McFarland 2006; Meyer et al. 1992). However, other studies found no significant effect (e.g., 
Hucker, Langevin, and Bain 1988; Maletzky 1991). ${ }^{2}$ Several studies have shown high efficacy rates for GnRH agonists in dramatically reducing testosterone levels and self-reported deviant sexual desires and behaviours, including in individuals who did not respond to CPA or MPA. However, no randomised controlled trials have yet been published (Thibaut et al. 2010). Thus, for both traditional agents and GnRH agonists, evidence for effectiveness is not robust. Moreover, chemical castration appears to be ineffective in antisocial or psychopathic sex offenders who do not suffer from paraphilia (Berlin 2009), and certain comorbidities may preclude effective intervention in individuals with paraphilia (Saleh and Guidry 2003).

\footnotetext{
${ }^{2}$ Most studies have investigated the effectiveness of "treatment" of sex offenders, where treatment typically consists in psychological therapy but may include chemical castration. Some review studies have shown a positive effect of psychiatric interventions (mainly psychotherapy, but in some cases also including chemical castration) on recidivism rates (Hall 1995; Hanson 2002; Gallagher et al. 1999; Lösel and Schmucker 2005), whereas others have not (Furby et al. 1989; Rice and Harris 2003). Moreover, there are substantial differences in the reported effect sizes (e.g., $d=.12$ in Hanson 2002; and $d=.47$ in Gallagher et al. 1999). Lösel and Schmucker (2005) found 37 percent less sexual recidivism in treated offenders compared to controls, with the highest treatment effect in biological treatment programs (i.e., chemical or surgical castration). A total of eight surgical castration studies and six chemical castration studies were included. Of the six chemical castration studies, only two found a significant reduction in recidivism rates. None of the castration studies involved an equivalent control group (Eher et al. 2007). In general, most of the studies included in these metaanalyses have methodological limitations (e.g., lack of a control group or nonequivalent control group, nonrandom participant assignment, small sample sizes) (Eher and Pfäfflin 2011). Nevertheless, according to a recent review by Eher and Pfäfflin, there is "evidence that treatment of sexual offender[s] is effective, as long as the program adheres to the principles of RNR [risks, needs, responsivity principles]" $(2011,9)$. A recent RNR-based meta-analysis (Hanson et al. 2009) found lower recidivism rates for treated sexual offenders compared to controls (10.9 percent versus 19.2 percent), similar to other metaanalyses (e.g., Lösel and Schmucker 2005: 11.1 percent versus 17.5 percent; Hanson 2002: 12.3 percent versus 16.8 percent). Although the authors originally planned to include chemical castration studies in their meta-analysis, none of these studies met their inclusion criteria regarding minimum level of study quality.
}

A range of negative adverse effects have been associated with chemical castration. Like surgical castration, it initiates andropause (a male equivalent of menopause) and may result in severe mood instability and, in some cases, clinical depression. It may also cause weight gain, insomnia, hot flushes, diabetes, feminization, migraine headaches, and, especially in cases of long-term use, bone demineralization (Garcia and Thibaut 2011).

Though some of these adverse effects occur regardless of the means of castration, GnRH agonists may achieve lower testosterone levels while having fewer side-effects than CPA and MPA (Garcia and Thibaut 2011; Rösler and Witztum 1998). However, the risk of bone demineralization remains and may require additional treatment (Dickey 2002; Garcia and Thibaut 2011; Rösler and Witztum 1998). Nevertheless, according to the World Federation of Societies of Biological Psychiatry (WFSBP), "[w]hen properly administered, with an appropriate protocol in place to detect and treat side effects should they develop, [GnRH agonist] treatments constitute no more or less of a risk than most other forms of frequently prescribed pharmacological agents" and constitute "the most promising treatment for sex offenders at high risk of sexual violence, such as paedophiles and serial rapists" (Thibaut et al. 2010, 643; Berlin 2009).

\section{Current Practice}

\section{The United States}

Currently, legislation in nine U.S. states allows for the castration of certain sex offenders (Scott and Holmberg 2003, 503; del Busto and Harlow 2011). Legislation in Georgia, Montana, Oregon, and Wisconsin provides for chemical castration only; California, Iowa, Florida, and Louisiana permit both chemical and surgical castration; and Texas allows only surgical castration. In some cases where chemical castration is offered it is formally optional and no link is made between refusal to consent to it and further incarceration; in others chemical castration is mandated as a condition of release; and in 
others still it is mandated with no formal link to release.

As an example of the latter practice, the Florida Statutes $(1997,794.0235)$ allow the courts in that state to sentence offenders who are convicted of sexual battery to chemical castration (via administration of MPA) either as a stand-alone remedy or in addition to more traditional criminal remedies. Chemical castration is not formally presented as an alternative to incarceration and indeed sentences involving MPA treatment may not be imposed in lieu of, or in return for a reduction of, any other penalty. However, an incarcerated offender who is required to undergo chemical castration on release may nevertheless face a de facto choice between chemical castration and further incarceration: He may refuse to comply with treatment, but if he does, this may result in a new conviction involving a felony of the second degree including further punishment. For offenders with a first conviction of sexual battery, the court has discretion over whether to include MPA treatment in the sentence, but for sexual offenders with a prior conviction of sexual battery, MPA treatment, contingent upon the assessment of a court-appointed medical expert, must be included in the sentence. The court order must specify the duration of the treatment, which may last from a few years up to the entire remaining life of the offender. However, the continued administration of MPA is not legally required if it is deemed medically inappropriate. Where offenders are sentenced to both incarceration and chemical castration, the chemical castration must start no later than one week prior to release.

\section{Europe}

In 2009, Polish President Lech Kaczynski signed a law allowing compulsory chemical castration for certain sex offenders at the end of their prison term. The law holds that certain sex offenders can be forced by the courts, after a psychiatric consultation, to undergo chemical castration upon release. However, the dominant approach in Europe is to offer chemical castration as a formally optional intervention.

In some cases, castration is presented as an alternative to continued incarceration. However, in other jurisdictions, the situation is more complex. For instance, in Belgium, psychiatric treatment may be made a formal condition of parole or temporary release (e.g., at weekends), ${ }^{3}$ but the precise nature of the treatment cannot be specified in advance by the penal authorities and offenders must always give their explicit consent to enter a specific treatment, such as chemical castration (Cosyns 1999 and personal comm.). However, if an offender under treatment is deemed to pose a critical danger to others, he may face continued incarceration (if he has not yet been released) or re-incarceration (if he has). This could occur, for example, because the offender declines chemical castration, or agrees to it, but then fails to comply with the treatment. Thus, though chemical castration is not formally presented as an alternative to further incarceration, it serves as a de facto alternative in the sense that declining to undergo castration increases the likelihood of continued incarceration or reincarceration.

\section{Castration, Coercion, and Consent}

In Florida, Belgium, and a number of other jurisdictions, chemical castration may be offered to sex offenders as either a formal or de facto alternative to further incarceration: Offenders may be presented with a choice between chemical castration and (certain or possible) further incarceration.

One common objection to offering chemical castration in these circumstances is that, since the offender's choice to undergo it is partly coerced-he faces the prospect of further incarceration if he refuses - his consent is not valid; that is to say, it does not serve its usual role of justifying the subsequent intervention. For example, Scott and Holmberg suggest that

[t]he most apparent ethics dilemma raised by [statutes authorising chemical or physical castration of sex offenders in several U.S. states] involves the extent that informed consent issues are sufficiently addressed with eligible offenders. The doctrine of informed consent requires that the individual be competent to

\footnotetext{
$\overline{3}$ Act of 13 April 1995 concerning sexual offences against minors; Act of 4 May 1999 concerning guidance and treatment of sexual offenders. See www.ufc.be, the website of the University Forensic Centre of Antwerp University Hospital (in Dutch).
} 
consent to treatment, that the consent be informed, and that the consent be given free of coercion (2003, 508, emphasis added).

Vanderzyl puts the point more emphatically, arguing that castration, whether chemical or surgical, "should be rejected as an unacceptable, ineffective and [in the United States] unconstitutional alternative to imprisonment" $(1994-1995,139)$. This is due to the "inherently coercive nature" of the choice between castration and incarceration:

the doctrine of informed consent requires a knowledgeable and voluntary decision to undergo treatment, yet offering a convicted offender castration as an alternative to a lengthy prison sentence constitutes an inherently coercive practice rendering truly voluntary consent impossible. Thus, castration should be rejected as a condition of probation (1994-1995, 140).

Similarly, in relation to the chemical or surgical castration of convicted rapists, William Green argues that

Voluntary consent depends upon a person's ability to make a choice freely. ... The convicted rapist is faced with two options - a lengthy prison sentence or even death on the one hand and Depo-Provera [MPA] or surgical castration on the other-and cannot be said to have the capacity to act freely in making a choice. Freedom of choice is impossible because the convict's loss of liberty constitutes a deprivation of such a magnitude that he cannot choose freely and voluntarily, but he is forced to give consent to an alternative he would not otherwise have chosen. In such circumstances men are willing to "barter their bodies." ... As a consequence, the convicted rapist cannot give voluntary consent to an offer of probation which contains a surgical castration or Depo-Provera condition (Green 1986, 16-17).

Finally, in its recent report on surgical castration in the Czech Republic, the Committee for the Prevention of Torture argued that

given the context in which the intervention is offered, it is questionable whether consent to the option of surgical castration will always be truly free and informed. As was found during the visit, a situation can easily arise whereby patients or prisoners acquiesce rather than consent, believing that it is the only available option to them to avoid indefinite confinement (Committee for the Prevention of Torture 2009, 20).

Though the Committee addressed only surgical castration, chemical castration offered in the same circumstances would presumably raise similar concerns about consent.

The argument contained in these passages, though never made fully explicit, appears to be as follows:

(1) An offender offered the choice between chemical castration and further incarceration cannot give valid consent to castration.

(2) Medical interventions should not be offered in circumstances where valid consent to them is not possible.

\section{Therefore}

(3) Chemical castration should not be offered as an alternative to further incarceration.

A common response to this argument has been to reject premise (1). It has been argued that though incarcerated offenders offered a choice between chemical castration and further incarceration clearly face pressure to consent to castration, that pressure does not render their consent invalid, for example because their choice is still (sufficiently) voluntary (Rosati 1994; BomannLarsen 2011). ${ }^{4}$ However, in this article, we will not pursue this line of argument. Instead, we will argue that, even when there is no hope of obtaining valid consent to chemical castration, offering it may be justified. Thus, we will deny premise (2), maintaining that this is one case in which medical interventions may sometimes permissibly be offered even if it will not be possible to obtain valid consent.

First, though, some simplifying assumptions. Throughout, we assume, unless specified otherwise, that chemical castration is to be offered to currently incarcerated offenders or paroled offenders as an alternative

\footnotetext{
$\overline{{ }^{4} \text { Also relevant }}$ in this connection: There is some evidence that the conditions under which crime-preventing medical interventions are agreed to by incarcerated offenders are not perceived as coercive by the offenders themselves. See, for example, Rigg (2002); Moser et al. (2004); Poythress et al. (2002); and Redlich et al. (2010).
} 
(or part of an alternative) to further incarceration. We do not consider whether chemical castration should be offered to sex offenders at the point of initial sentencing, nor whether it should be offered to individuals who have never offended but are at risk of doing so. We also set aside the possibility that chemical castration might be offered in such a way that acceptance of the offer will have no effect on the length or conditions of the offender's incarceration. Though this might alleviate concerns regarding the validity of consent, there may be good reasons not to take this route. Arguably there are, in many cases, reasons for the state to tailor the length of an offender's incarceration to his risk of re-offending, and since undergoing chemical castration might lower this risk in some cases, the state could have good reason to respond by reducing the length of incarceration. Moreover, insofar as chemical castration constitutes a sacrifice made in the interests of the public, there might also be fairness-based arguments for "rewarding" those offenders who choose to undergo castration with a diminished period of incarceration. For the sake of argument, we assume (though do not claim to have established) that if chemical castration is to be offered to offenders, it should be offered in return for at least some reduction in the length of incarceration.

In addition, we assume that the length of time spent incarcerated if the offender declines chemical castration will be no longer than the time he would have spent incarcerated had chemical castration not been offered. Thus, relative to the situation in which no chemical castration is offered, agreeing to undergo chemical castration reduces the amount of time that the offender spends in incarceration rather than preventing an increase. (This is obviously not the case in Florida.)

Third, we assume throughout that the party which must decide whether to offer chemical castration is the state, rather than, say, individual forensic or medical professionals or agencies. Our question is whether it may be permissible for the state to offer chemical castration as an alternative to further incarceration. We consider the proper role of psychiatrists, parole boards, judges, and so on only insofar as this is relevant to that question.

Fourth, we assume that chemical castration is effective at preventing recidivism in at least some welldefined classes of sex offender. There is currently no robust evidence to support this assumption (Rice and Harris 2011, 315), however it would be unsurprising if it were accurate, since chemical castration does attenuate sexual desires and has in some cases been shown to eliminate deviant sexual desires and behaviours (Briken, Hill, and Berner 2003). Moreover, even if chemical castration is not yet effective at preventing reoffending, it may well become so in the near future.

Fifth, we assume that chemical castration will be continued only so long as there are no serious sideeffects. Thus, we do not consider objections to our argument that rely on the presence of such side-effects.

Finally, a note on terminology. We henceforth use the terms "chemical castration" and "castration" interchangeably to refer only to "chemical castration".

\section{Enhancing Future Autonomy}

Suppose, for the sake of argument, that it is not possible to obtain valid consent to chemical castration in the contexts we are considering - i.e., those in which castration is being offered as an alternative to further incarceration. In that case, it might seem that the state could not permissibly provide castration, because medical interventions may only be provided with the valid consent of the recipient (call this "the consent requirement").

It is, however, worth inquiring why valid consent must be obtained prior to providing castration in these cases. A standard justification for adopting the consent requirement is that satisfying it is necessary for (or at least conducive to) adequately protecting the autono$m y$ of the patient - that is, roughly, the patient's control over his life. Performing medical procedures on competent adults without valid consent is wrong because it seriously threatens their autonomy.

If obtaining valid consent from an individual is important because it helps to protect that person's autonomy, one might question whether valid consent must always be obtained for medical interventions that will increase autonomy. Chemical castration will often do exactly that. Consider this hypothetical case:

Jeremy, a 55-year-old man, is currently five years into an eight-year sentence handed down for the rape of a 10-year-old boy. He has a history of recurrent sexual abuse of children and has previously been imprisoned twice for this. Each time, following release, he has reoffended. He despises the kind of person he has become, feels some remorse for the victims of his crime, and feels that he has been disowned by his family and society. He experiences his 
sexual desires as unwanted intrusions on his mental life and is unable to purge inappropriate sexual thoughts from his mind for more than a few minutes. He tries to resist acting on these desires and sometimes succeeds for a period of time, but he inevitably succumbs eventually. Resigned to the fact that the desires are for all practical purposes irresistible, he wants nothing more than to be free from them. He elects to undergo chemical castration as part of a parole agreement and finds that, as a result of this intervention, his inappropriate sexual desires become significantly less frequent and weaker. He discovers that, not only is he now able to resist acting on these desires when they are present, he is also able to pursue various other projects and interests now that his mind is not overwhelmed by sexual thoughts. ${ }^{5}$

Plausibly, Jeremy's sexual desires were themselves impediments to autonomy. If so, then attenuating those desires via chemical castration will tend to increase his autonomy. Thus, it might seem that withholding castration from Jeremy on the grounds that he could not give valid consent would have the paradoxical result of restricting his autonomy. This is paradoxical because the very point of obtaining consent is, arguably, to protect autonomy.

Of course, Jeremy's case is an extreme one. In almost all actual cases, the offender's views and motives will be far messier. But in many messier and less extreme cases too, the desires that lead sex offenders to offend seem aptly construed as impediments to autonomy. Precisely when a desire counts as a constraint on autonomy would be controversial. On a rationalist account of autonomy, all irrational desires restrict one's autonomy. Desires may be said to be irrational when, for example, they are based on logical errors, false beliefs, or a failure to consider relevant information or to vividly imagine relevant outcomes (Brandt 1979, 110-129; Savulescu 1994, 193-202). Other approaches to autonomy stress that, to be autonomous, one's actions must not be driven by desires that one does not reflectively endorse or that are alien to the authentic self (Dworkin 1989; Frankfurt 1971; Schechtman 2004). Desires that motivate sexual offences will often qualify as impediments to autonomy on all of these views. In these cases, it is very plausible

\footnotetext{
${ }^{5}$ For a description and discussion of a somewhat similar reallife case, see Alexander et al. (1993).
}

that, if chemical castration would attenuate these desires, it would increase autonomy. ${ }^{6}$

In addition to perhaps attenuating autonomyrestricting desires, chemical castration, where undergone as an alternative to further incarceration, may be conducive to an offender's autonomy in another, more obvious way. Pursuant to our second assumption above, agreeing to undergo castration reduces the amount of time that the offender will spend incarcerated compared to the scenario in which castration is not offered; it results in the earlier removal of those constraints on free movement, free association, and free expression that are entailed by incarceration. It is true that similar gains in autonomy could be obtained by simply removing those constraints regardless of whether the offender undergoes castration. However, in many cases there may be sufficient reasons not to do this; for example, the risks to society may be too great. Having justifiably excluded the possibility that an offender will neither be incarcerated nor castrated, castration will typically be the remaining course of action that is most conducive to the offender's freedom of movement, association, and expression.

Where chemical castration increases future autonomy overall, either by removing internal barriers (such as irrational, inauthentic, compulsive desires) or external ones (such as restrictions on free movement), it might seem counterproductive to withhold chemical castration so as not to violate the consent requirement. One reason to respect that requirement is to protect the autonomy of the individual concerned, but in these cases, offering the intervention seems to be the option most conducive to autonomy.

\section{Respecting Present Autonomy}

At this point it might be objected that, insofar as considerations of autonomy bear on the state's provision of medical interventions, the primary goal should

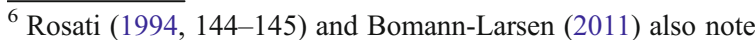
that chemical castration and other medical interventions aimed at criminal rehabilitation will often increase autonomy. However, they do not draw out the implications of this point for the question whether valid consent must be obtained in these cases. Similar ideas have also been discussed in other contexts. Arthur Caplan (2006) claims that a concern to enhance autonomy may justify forced treatments for drug addicts, while John Stuart Mill $(1863,186)$ maintains that it may be justified to forcibly restrain an individual about to unknowingly expose himself to serious physical danger.
} 
be not to protect or increase the future autonomy of the recipient, but to avoid actively decreasing his present autonomy: What is most important is that the state does not actively bring it about that an individual enjoys less autonomy in the present than he would otherwise have enjoyed. ${ }^{7}$ (This may be one of the thoughts expressed by the oft-heard admonition to respect autonomy.)

If this view is correct, then it will usually be unjustified for the state to actively decrease an agent's autonomy now, even if it does so in order to enhance or protect his overall future autonomy. At least, this will be unjustified unless the future gain in autonomy would greatly exceed the present decrease (Caplan 2006). To illustrate: It is plausible, on some accounts of autonomy, that mild depression constitutes at least a minor impediment to autonomy. On these accounts, treating mild depression will often increase future autonomy. Nevertheless, we would not normally think it permissible for the state to forcibly treat a mildly depressed person, thus actively decreasing his autonomy now, even if we thought this would somewhat increase his autonomy in the future. Similarly, it might be argued that, even where chemical castration would likely increase the future autonomy of a sex offender, the state would not be justified in providing it in coercive contexts, such as those under consideration here. Doing so would involve actively decreasing current autonomy for the sake of a gain in future autonomy.

There are at least two problems with this argument, however. First, the desires that drive many sex offenders may frequently constitute very severe impediments to autonomy. Medical staff involved in treating sex offenders report that they are frequently virtually unable to think about anything but sex because of intrusive sexual desires (Thibaut et al. 2010; P. Cosyns, personal comm.). Assuming those desires are impediments to autonomy, it seems plausible, given their intrusiveness, that they are serious impediments. This suggests that it might be justifiable to actively constrain the present autonomy of such offenders to some degree in order to attenuate these desires in the future. After all, in other situations where autonomy is often thought to be seriously constrained - for example, in severe addiction or

\footnotetext{
${ }^{7}$ Different views would be offered on what constitutes an active decrease or restriction. On one view, an active decrease would be one that is intended rather than merely foreseen. On another, an active decrease would be one that follows from an act rather than an omission.
}

substantial cognitive impairment - it is often thought acceptable to tolerate some active reduction in present autonomy in order to enhance future autonomy.

More importantly, though, it is not clear that there is any active reduction in present autonomy in the cases with which we are concerned. Even where chemical castration is offered to an offender in somewhat coercive circumstances, making the offer need not decrease the present autonomy of the offender in the sense of making the offender less autonomous than he would otherwise have been. Indeed, other things being equal, offering the offender a choice between castration and further incarceration rather than merely further incarceration will make him more autonomous right from the moment that castration is offered. It does this by expanding the number of alternatives open to him.

It is true that an offender given the choice between chemical castration and incarceration is still quite heavily constrained-more heavily constrained than a typical patient in non-penal contexts. But the crucial point is that he is less constrained than he would have been had he not been offered castration. This may seem an obvious point, but it is one that has often been missed by those who have raised autonomyrelated concerns about chemical castration. (For example, this point is not acknowledged by any of the opponents of chemical castration quoted in the section "Castration, Coercion, and Consent" above.)

\section{A Clarification}

At this point we should make an important clarification. We have suggested that undergoing chemical castration will often increase an offender's future autonomy, in part by attenuating irrational or inauthentic sexual desires. We have also argued that offering chemical castration to an offender will often increase his present autonomy by expanding the number of options available to him. However, we are not claiming that an offender's autonomy will always be increased in these ways.

Expanding the number of alternatives open to a person does not always increase autonomy. For example, there is a sense in which the heroin addict who has the option of taking a shot of heroin has less autonomy than the heroin addict with no access to the drug. Arguably, offering an alternative for which a person has a powerful and irrational or inauthentic desire reduces autonomy (Radin 1987; Walzer 1983). There may be some cases in 
which a sex offender's desire to undergo chemical castration, thus avoiding incarceration, is of this sort. For, example, the offender may have an irrational fear of imprisonment (Appel 2012). Or he may accept castration out of a desire to conform to social pressures that he does not in fact endorse - a desire that might, on some views, count as inauthentic.

However, the decision to undergo castration in preference to further incarceration need not always be motivated by irrational or inauthentic desires (Rosati 1994). Many offenders would arrive at the decision to undergo castration on the basis of adequately calm, rational, and authentic consideration of what will give them the best life or best help them to overcome their affliction. Giving such offenders the option of castration in addition to incarceration would tend to increase their autonomy by increasing the number of alternatives available to them.

Similarly, attenuating deviant sexual desires may not always increase an offender's autonomy. Consider an offender who is proud of his deviant desires, believes that in acting on them he does no wrong, and identifies with those desires wholeheartedly. In most jurisdictions, it is unlikely that this offender would be offered castration. Sex offenders who (a) exhibit no paraphilia, (b) suffer from severe psychiatric comorbidity, or (c) are in denial concerning the wrongness of their actions are typically not considered eligible candidates for chemical castration by experienced psychiatrists (e.g., Berlin 2009, 59; Cosyns 1999, 403; Wong 2001). However, if castration were offered and accepted in this sort of case- perhaps in a jurisdiction where no prior psychiatric assessment is required —one might question whether it would enhance the offender's autonomy. Arguably, attenuating the sexual desires of such an individual would not alleviate any constraint on his autonomy, for those desires might seem to be part of the offender's autonomous self, not constraints on it. This would be plausible, for example, on accounts of autonomy according to which what matters for autonomy is that one reflectively endorses one's desires (e.g., Frankfurt 1971). It might also be plausible on views according to which one must reflectively endorse one's desires and do so authentically (e.g., Dworkin 1989), for it is not clear than anything inauthentic is going on in this offender's endorsement of his deviant sexual desires.

Note, however, that on other accounts of autonomy it is less clear that deviant sexual desires that motivate sexual offending could qualify as part of the autonomous self. For example, it is not clear that such desires could ever be rational, so it is not clear that they could be part of the autonomous self on a rationalist account of autonomy.

More importantly, even if these desires would qualify as part of the autonomous self in some sex offenders, they would not in others. There are many sex offenders whose sexual desires would qualify as impediments to autonomy on any plausible account of autonomy. For example, there are surely many sex offenders in whom sexual desires are neither rational nor reflectively endorsed. This is enough to sustain our claim that attenuating the sexual desires of sex offenders will often increase their future autonomy.

\section{Justified Constraints on Autonomy}

We have argued that undergoing chemical castration will often increase an offender's overall future autonomy by attenuating internal barriers to autonomy and by allowing for the removal of external ones. We have also argued that offering castration to incarcerated offenders need not actively reduce the offender's present autonomy and indeed will typically increase it. This is because offering chemical castration expands the options open to the offender compared to withholding castration. We can thus expect that there will be many cases in which offering chemical castration does not actively diminish the offender's autonomy in the present (or, for that matter, at any other point) and in fact increases both current and overall future autonomy. In these cases, a concern for the offender's autonomy-the concern that underpins worries about consent-will militate in favour of offering castration, not against it.

It is true, of course, that a sex offender offered the choice between chemical castration and further incarceration enjoys markedly less autonomy than many ordinary patients: He may be incarcerated if he does not agree to and comply with the invention being offered. Presumably, this is what worries opponents of chemical castration. Perhaps their thought is that, even if offering castration increases the present and future autonomy of the sex offender, the offender's autonomy is still unjustifiably constrained. The offender still has less autonomy than comparable non-offenders who choose 
to undergo similarly invasive interventions and perhaps that is morally problematic.

However, it is doubtful whether offenders presented with the choice between incarceration and chemical castration are unjustifiably constrained. It is often thought that, in committing crimes, offenders have made themselves liable to certain interventions that restrict autonomy, with incarceration being the paradigmatic example. Because they have committed crimes, offenders may justifiably have their autonomy constrained in order to protect the wider interests of society. By contrast, it is not justifiable to incarcerate an ordinary citizen who has done nothing to make herself liable to such a constraint on autonomy. ${ }^{8}$ Suppose that the incarceration of sex offenders can be justified in this way. It is then difficult to see how offering to shorten the period of incarceration in return for agreement to undergo chemical castration could fail to be justified. If our argument above is sound, adding this option will often increase the present and future autonomy of the offender without actively decreasing it at any point. If the initial restriction of autonomy brought about through incarceration was itself justified, then it is difficult to see how the lesser (but still significant) restriction on autonomy faced by the offender offered a choice between incarceration and castration could be unjustified. (Though concerns might be raised here about whether it is appropriate, for reasons other than those of autonomy, for the state to offer chemical castration. See, for a discussion, Bomann-Larsen 2011.)

\section{Unjustified Incarceration Practices}

But what if current incarceration practices constitute unjustified restrictions of autonomy? By committing crimes, offenders may have made themselves liable to some kinds of punishment, but that does not exclude the possibility that actual incarceration practices, at least in some jurisdictions, are unjustified. In many jurisdictions, incarcerated offenders are at high risk of becoming victims of rape, assault, or even murder.

\footnotetext{
${ }^{8}$ Incarceration of non-criminals, or equivalent restrictions on freedom of movement, association, and expression, may be justified in some extreme cases, for example, in the context of pandemic control. But the threshold for incarcerating a non-criminal is plausibly much higher than it is for a criminal offender.
}

They frequently have limited access to basic resources such as ordinary medical care (Stern 2001). In some jurisdictions they are subjected to gruelling forced labour and may even have organs removed against their will (Caplan et al. 2011). How do our arguments apply when prevailing incarceration practices are unjustified?

It might be thought that, if prevailing incarceration practices are unjustified, this merely strengthens our argument. We have argued that offering chemical castration as an alternative to further incarceration will often not actively decrease, and will indeed increase, the offender's autonomy. ${ }^{9}$ If incarceration, as it is currently done, is an unjustified infringement of autonomy, it might be thought that we have particularly strong reasons to enhance the autonomy of incarcerated sex offenders and thus to offer castration as an alternative.

However, this is too quick. Our autonomy-based argument for the permissibility of offering chemical castration to incarcerated sex offenders relies on taking the initial, autonomy-restricted situation of the sex offenders as a baseline from which gains or losses in autonomy can be measured. It appeals to the thought that offering castration will be justified where it does not actively decrease, and indeed increases, the offender's autonomy from that baseline. But whether the initial autonomy-restricted situation may be taken as a baseline in this way depends on whether it is itself justified. To see this, consider a case in which $A$ kidnaps $B$ 's child, and then offers to release the child if $B$ pays $A$ a ransom (The case is modified from Cohen 1991, especially 276-279). Clearly, this offer does not decrease, and indeed increases, $B$ 's autonomy relative to the baseline in which no such offer is made. However, this does not justify making the offer, since the baseline situation - the one in which $B$ 's child is kept hostage - is itself unjustifiably imposed by $A$. What $A$ should do is remedy that situation; he should release the child without requiring a ransom. Similarly, it might be argued that if current incarceration practices are unjustified, then, rather than offering chemical castration as an alternative, what the state should do is reform those practices. If prevailing incarceration practices are not justified, then it may not be possible

\footnotetext{
${ }^{9}$ For a discussion of circumstances in which offering chemical castration might not increase autonomy, see the section on "Implications" below.
} 
to take them as a baseline in the way that is required for our argument to succeed.

\section{Implications}

We have set out an autonomy-based argument in favour of offering chemical castration as an alternative to further incarceration for certain sex offenders. However, we have also noted a possible limit to the argument's scope: It may be unpersuasive in cases where prevailing incarceration practices are unjustified.

What are the implications of our argument? Since autonomy is only one consideration relevant to public policy on chemical castration, one cannot straightforwardly infer from our argument that, all things considered, chemical castration should or even may, in some cases, be offered as an alternative to further incarceration. We believe that our argument strengthens the case for offering chemical castration in some circumstances, but it may be that there are always decisive countervailing reasons against offering castration. For example, it may be that offering chemical castration would diminish the deterrent effect of criminal justice systems, would unduly harm those who undergo the procedure, or would violate norms regarding the proper role of the state in providing medical procedures. It is possible that one or more of these considerations would invariably outweigh the autonomy-based reasons in favour of offering castration that we have identified.

However, suppose that our argument does justify offering chemical castration. Suppose, that is, that considerations of autonomy count decisively in favour of offering chemical castration in some cases. What can we say about the way in which castration ought to be provided?

Several safeguards ought to be placed on the provision of chemical castration. Some of these would seem necessary even leaving aside considerations of autonomy. For example, it is surely of the utmost importance that a psychiatrist and physician assess whether castration is medically safe and likely to be effective at diminishing deviant sexual desires and behaviour. Similarly, we suggest that chemical castration ought to be accompanied by psychotherapy, since this may substantially increase the effectiveness of the intervention (Thibaut et al. 2010). These safeguards could be justified by a concern for nonmaleficence and effectiveness in crime prevention. However, a concern for autonomy may strengthen the case for such safeguards, since offering ineffective interventions is unlikely to significantly enhance present or future autonomy.

Moreover, our arguments do suggest a possible need for at least one further safeguard. We noted above that our autonomy-based argument for offering chemical castration as an alternative to incarceration might fail in cases where prevailing incarceration practices are themselves unjustified. This suggests the possible need for policies ensuring that incarceration practices are improved before chemical castration is offered as an alternative to them. An interesting question, of course, is precisely how ethically sound our incarceration practices must be in order for it to be permissible to offer castration as an alternative. This is a complex question that we cannot answer here.

\section{Conclusion}

Some have argued that the state should not offer sexual offenders the choice between chemical castration and further incarceration because valid consent cannot be obtained in these circumstances. The consent requirement would not be satisfied.

However, we have argued that the concerns that arguably underpin this objection-concerns about autonomy - will in fact support offering chemical castration in certain cases, even where valid consent could not be obtained. We began by noting that castration may increase the offender's future autonomy by removing internal, psychological barriers to autonomy, such as irresistible sexual urges, and by allowing the offender to be released from prison, thus reducing restrictions on freedom of movement, association, and expression. We acknowledged that offering castration might still be unjustified if doing so would actively decrease the offender's present autonomy. However, we argued that it need not do so. Indeed, offering castration will often increase the offender's present autonomy by increasing the number of alternatives open to the offender. There will thus be cases in which offering chemical castration increases the overall present and future autonomy of the offender and without actively decreasing it at any point. In 
these cases, considerations of autonomy would count in favour of offering castration.

We then discussed a practically significant limitation to our argument: It may not be persuasive in cases where prevailing incarceration practices are unjustified. Finally, we discussed some possible implications. We noted that, though our argument strengthens the case for offering chemical castration as an alternative to further incarceration in certain cases, the abovementioned limitation also suggests a possible need to ensure that incarceration practices be reformed before this alternative is offered.

Acknowledgments The authors would like to thank Professor Paul Cosyns and Tine Vertommen for providing guidance on the empirical aspects of the article.

Competing Interests The authors declare that they have no competing interests.

Funding Support Douglas, Bonte, Devolder, and Focquaert received funding from Research Foundation Flanders (FWO). Douglas received funding from the Wellcome Trust (grant number WT087211).

Open Access This article is distributed under the terms of the Creative Commons Attribution License which permits any use, distribution, and reproduction in any medium, provided the original author(s) and the source are credited.

\section{References}

Alexander, M., J. Gunn, D.A. Cook, P.J. Taylor, and J. Finch. 1993. Should a sexual offender be allowed castration? British Medical Journal 307(6907): 790-793.

Appel, J. 2012. Castration anxiety: Physicians, "do no harm," and chemical castration laws. Journal of Bioethical Inquiry 9(1): 85-91.

Berlin, F.S. 2009. Commentary: Risk/benefit ratio of androgen deprivation treatment for sex offenders. The Journal of the American Academy of Psychiatry and the Law 37(1): 59-62.

Bomann-Larsen, L. 2011. Voluntary rehabilitation? On neurotechnological behavioural treatment, valid consent and (in)appropriate offers. Neuroethics 6(1): 65-77.

Bradford, J.M.W. 2001. The neurobiology, neuropharmacology, and pharmacological treatment of the paraphilias and compulsive sexual behaviour. Canadian Journal of Psychiatry/ Revue Canadienne de Psychiatrie 46(1): 26-34.

Brandt, R.B. 1979. A theory of the good and the right. Oxford: Clarendon.

Briken, P., A. Hill, and W. Berner. 2003. Pharmacotherapy of paraphilias with long-acting agonists of luteinizing hormone-releasing hormone: A systematic review. The Journal of Clinical Psychiatry 64(8): 890-897.
Caplan, A.L. 2006. Ethical issues surrounding forced, mandated, or coerced treatment. Journal of Substance Abuse Treatment 31(2): 117-120.

Caplan, A.L., G. Danovitch, M. Shapiro, J. Lavee, and M. Epstein. 2011. Time for a boycott of Chinese science and medicine pertaining to organ transplantation. The Lancet 378(9798): 1218.

Cohen, G.E. 1991. Incentives, inequality, and community. Paper presented at The Tanner Lectures on Human Values, May 21 and 23, at Stanford University in Palo Alto, CA. http:// tannerlectures.utah.edu/lectures/documents/cohen92.pdf.

Cosyns, P. 1999. Treatment of sexual abusers in Belgium. Journal of Interpersonal Violence 14(4): 396-410.

del Busto, E., and M.C. Harlow. 2011. American sexual offender castration treatment and legislation. In International perspectives on the assessment and treatment of sexual offenders: Theory, practice, and research, ed. D.P. Boer, R. Eher, L.E. Craig, M.H. Miner, and F. Pfäfflin, 543-571. Oxford: Wiley-Blackwell.

Dickey, R. 2002. Case report: The management of bone demineralization associated with long-term treatment of multiple paraphilias with long-acting LHRH agonists. Journal of Sex \& Marital Therapy 28(3): 207-210.

Dworkin, G. 1989. The concept of autonomy. In The inner citadel: Essays on individual autonomy, ed. J. Christman, 54-62. Oxford and New York: Oxford University Press.

Eher, R., A. Gnoth, A. Birklbauerl, and F. Pfäfflin. 2007. The effects of antiandrogenic medication on relapse rates of sex offenders: A review. Recht und Psychiatrie 25(3): 103-111.

Eher, R., and F. Pfäfflin. 2011. Adult sexual offender treatment - is it effective? In International perspectives on the assessment and treatment of sexual offenders: Theory, practice, and research, ed. D.P. Boer, R. Eher, L.E. Craig, M.H. Miner, and F. Pfäfflin, 3-12. Oxford: Wiley-Blackwell.

European Committee for the Prevention of Torture and Inhuman or Degrading Treatment or Punishment. 2009. Report to the Czech Government on the visit to the Czech Republic carried out by the European Committee for the Prevention of Torture and Inhuman or Degrading Treatment or Punishment (CPT). Strasbourg: The Council of Europe. http:// www.cpt.coe.int/documents/cze/2009-08-inf-eng.pdf.

Fedoroff, J.P., R. Wisner-Carlson, S. Dean, and F.S. Berlin. 1992. Medroxy-progesterone acetate in the treatment of paraphilic sexual disorders: Rate of relapse in paraphilic men treated in long-term group psychotherapy with or without medroxy-progesterone acetate. Journal of Offender Rehabilitation 18(3-4): 109-123.

Frankfurt, H.G. 1971. Freedom of the will and the concept of a person. Journal of Philosophy 68(1): 5-20.

Furby, L., M.R. Weinrott, and L. Blackshaw. 1989. Sex offender recidivism: A review. Psychological Bulletin 105(1): 3-30.

Gallagher, C.A., D.B. Wilson, P. Hirschfeld, M.B. Coggeshall, and D.L. MacKenzie. 1999. Quantitative review of the effects of sex offender treatment on sexual reoffending. Corrections Management Quarterly 3(4): 19-29.

Garcia, F.D., and F. Thibaut. 2011. Current concepts in the pharmacotherapy of paraphilias. Drugs 71(6): 771-790.

Gordon, H., and D. Grubin. 2004. Psychiatric aspects of the assessment and treatment of sex offenders. Advances in Psychiatric Treatment 10(1): 73-80. 
Green, W. 1986. Depo-Provera, castration, and the probation of rape offenders: Statutory and constitutional issues. University of Dayton Law Review 12(1): 1-26.

Hall, G.C.N. 1995. The preliminary development of theorybased community treatment for sexual offenders. Professional Psychology: Research and Practice 26(5): 478-483.

Hanson, R.K. 2002. Recidivism and age: Follow-up data from 4,673 sexual offenders. Journal of Interpersonal Violence 17(10): 1046-1062.

Hanson, R.K., G. Bourgon, L. Helmus, and S. Hodgson. 2009. The principles of effective correctional treatment also apply to sexual offenders a meta-analysis. Criminal Justice and Behavior 36(9): 865-891.

Heim, N., and C.J. Hursch. 1979. Castration for sex offenders: Treatment or punishment? A review and critique of recent European literature. Archives of Sexual Behavior 8(3): 281-304.

Hucker, S., R. Langevin, and J. Bain. 1988. A double blind trial of sex drive reducing medication in pedophiles. Sexual Abuse: A Journal of Research and Treatment 1(2): 227-242.

Kasper, P. 2001. Cyproterone acetate: A genotoxic carcinogen? Pharmacology and Toxicology 88(5): 223-231.

Lösel, F., and M. Schmucker. 2005. The effectiveness of treatment for sexual offenders: A comprehensive meta-analysis. Journal of Experimental Criminology 1(1): 117-146.

Maletzky, B.M. 1991. The use of medroxyprogesterone acetate to assist in the treatment of sexual offenders. Annals of Sex Research 4(2): 117-129.

Maletzky, B.M., A. Tolan, and B. McFarland. 2006. The Oregon Depo-Provera program: A five-year follow-up. Sexual Abuse: A Journal of Research and Treatment 18(3): 303-316.

Meyer 3rd, W.J., C. Cole, and E. Emory. 1992. Depo-Provera treatment for sex offending behavior: An evaluation of outcome. The Bulletin of the American Academy of Psychiatry and the Law 20(3): 249-259.

Mill, J.S. 1863. On liberty. Boston: Ticknor and Fields.

Moser, D.J., S. Arndt, J.E. Kanz, M.L. Benjamin, J.D. Bayless, and R.L. Reese. 2004. Coercion and informed consent in research involving prisoners. Comprehensive Psychiatry 45(1): 1-9.

Neumann, I., D. Thierau, U. Andrae, H. Greim, and L.R. Schwarz. 1992. Cyproterone-acetate induces DNA damage in cultured rat hepatocytes and preferentially stimulates DNA-synthesis in gamma-glutamyltranspeptidase-positive cells. Carcinogenesis 13(3): 373-378.

Poythress, N.G., J. Petrila, A. McGaha, and R. Boothroyd. 2002. Perceived coercion and procedural justice in the Broward mental health court. International Journal of Law and Psychiatry 25(5): 517-533.

Radin, M.J. 1987. Market-inalienability. Harvard Law Review 100(8): 1849-1937.

Redlich, A.D., S. Hoover, A. Summers, and H.J. Steadman. 2010. Enrollment in mental health courts: Voluntariness, knowingness, and adjudicative competence. Law and Human Behavior 34(2): 91-104.

Rice, M.E., and G.T. Harris. 2003. The size and sign of treatment effects in sex offender therapy. Sexually Coercive Behavior: Understanding and Management 989(June): 428-440.

Rice, M.E., and G.T. Harris. 2011. Is Androgen deprivation therapy effective in the treatment of sex offenders? Psychology, Public Policy, and Law 17(2): 315-332.

Rigg, J. 2002. Measures of perceived coercion in prison treatment settings. International Journal of Law and Psychiatry 25(5): 473-490.

Rosati, C. 1994. A study of internal punishment. Wisconsin Law Review 123: 123-170.

Rösler, A., and E. Witztum. 1998. Treatment of men with paraphilia with a long-acting analogue of gonadotropin-releasing hormone. New England Journal of Medicine 338(7): 416-422.

Saleh, F.M., and L.L. Guidry. 2003. Psychosocial and biological treatment considerations for the paraphilic and nonparaphilic sex offender. The Journal of the American Academy of Psychiatry and the Law 31(4): 486-493.

Savulescu, J. 1994. Rational desires and the limitation of lifesustaining treatment. Bioethics 8(3): 191-222.

Schechtman, M. 2004. Self-expression and self-control. Ratio 17(4): 409-427.

Scott, C.L., and T. Holmberg. 2003. Castration of sex offenders: Prisoners' rights versus public safety. The Journal of the American Academy of Psychiatry and the Law 31(4): 502-509.

Stern, V. 2001. Problems in prisons worldwide, with a particular focus on Russia. Annals of the New York Academy of Sciences 953b(1): 113-119.

Thibaut, F., F. De La Barra, H. Gordon, P. Cosyns, J.M.W. Bradford, and WFSBP Task Force on Sexual Disorders. 2010. The World Federation of Societies of Biological Psychiatry (WFSBP) Guidelines for the biological treatment of paraphilias. The World Journal of Biological Psychiatry 11(4): 604-655.

Vanderzyl, K.A. 1994-1995. Castration as an alternative to incarceration: An impotent approach to the punishment of sex offenders. Northern Illinois University Law Review 15: 107-140.

Walzer, M. 1983. Spheres of justice: A defense of pluralism and equality. New York: Basic Books.

Weinberger, L.E., S. Sreenivasan, T. Garrick, and H. Osran. 2005. The impact of surgical castration on sexual recidivism risk among sexually violent predatory offenders. The Journal of the American Academy of Psychiatry and the Law 33(1): 16-36.

Wille, R., and K.M. Beier. 1989. Castration in Germany. Annals of Sex Research 2(2): 103-133.

Wong, C.M. 2001. Chemical castration: Oregon's innovative approach to sex offender rehabilitation, or unconstitutional punishment? Oregon Law Review 80: 267-301. 